\title{
Short and Long-Term Interest Rates and the Effectiveness of Monetary and Macroprudential Policies
}

\author{
Margarita Rubio* \\ University of Nottingham
}

September 2015

\begin{abstract}
In this paper, I analyze the ability of monetary and macroprudential policies to stabilize both the macroeconomy and financial markets under two different scenarios: short and long-term rates. I develop and solve a New Keynesian dynamic stochastic general equilibrium model that features a housing market, borrowers and savers. Borrowers can access credit markets through their housing collateral. I consider two alternative ways of introducing a macroprudential approach to enhance financial stability: one in which monetary policy, using the interest rate as an instrument, responds to credit growth; and a second one in which the macroprudential instrument is instead the loan-to-value ratio (LTV). Results show that monetary and macroprudential policies are less effective with longterm rates. However, in the short-term case, monetary policy can achieve the financial stability goal only at the expense of higher macroeconomic volatility. If the macroprudential policy is implemented using an LTV rule, financial stability improves significantly with short-term rates but just marginally with long-term ones.
\end{abstract}

Keywords: Short and long-term interest rate, monetary policy, macroprudential policy, LTV, housing market

JEL Codes: E32, E44, E52

${ }^{*}$ The author would like to thank Matteo Iacoviello, Fabio Ghironi and Peter Ireland for their support and help in the modelling framework. Special thanks to José A. Carrasco-Gallego for his very useful comments. Part of this project was undertaken while the author was visiting the National Bank of Poland, for which she acknowledges their hospitality. All errors are mine. 
" In my remarks, I will argue that monetary policy faces significant limitations as a tool to promote financial stability [...] If monetary policy is not to play a central role in addressing financial stability issues, this task must rely on macroprudential policies [...] But experience with such tools remains limited, and we have much to learn to use these measures effectively". Chair Janet L. Yellen, July 2, 2014.

\section{Introduction}

The ability of monetary policy to affect the economy has been the center of macroeconomic research in recent years. Both theoretical and empirical work has focused on studying the channels and the strength of the monetary policy transmission mechanism. We know now that there are some circumstances under which monetary policy looses its power as a tool to stabilize the macroeconomy. In the aftermath of the financial crisis we understand that monetary policy has its limits and that it is not only macroeconomic stability what matters. In recent times, the focus of policy and academic discussions has been how to ensure a more stable financial system: a macroprudential approach to prevent the economy from situations in which problems in the financial sector are transmitted to the real sector and vice-versa. However, it is debatable whether monetary policy alone can achieve this goal; it may need the help of other tools to avoid excessive credit growth.

Along the years, new experiences have revealed that the effectiveness of monetary policy may depend on structural factors in the economy. For example, mortgage interest rates adjust not only to changes in short-term interest rates but also to longer-term ones. Institutional features make that the prevalent rate in the economy is short or long term. For instance, regulation may make that institutions switch towards longer-term, fixed-rate mortgage loans in some countries, while they are linked to short-term rates in some others. Long-term rates create a source of interest rate sluggishness, since these rates are slower to change. These features may affect the transmission and optimal conduct of policies. As Boivin et al. (2010) point out, the entire expected path of interest rates, not solely the current value, influences asset prices and spending. Even though the monetary policy instrument is a short-term interest rate, the monetary transmission mechanism involves the link between short and long-term interest rates. For example, when monetary policy raises short-term interest rates, long-term interest rates also tend to rise because they are linked to future short-term rates. Therefore, when rates are tied to longer rates, the link between the policy rate and the retail rate is weaker. And in fact, this slow adjustment in the 
long-term interest rate may make monetary policy less effective. The remaining question is the following: Do short and long-term interest rates also affect the ability of monetary and macroprudential policies to enhance financial stability?

In this paper, I try to shed some light on this issue. I analyze the ability of monetary policy to stabilize financial markets and the macroeconomy when mortgage interest rates are sluggish because they are linked to longer-term rates. Recent literature shows that the effectiveness of monetary policy to stabilize the macroeconomy is reduced when mortgage rates are fixed or tied to longer rates. Nevertheless, there is no consensus on whether this feature has an impact on the potential of monetary and macroprudential policies to promote financial stability.

Most of the standard models used in central banks fail at introducing longer-term rates, they are usually based on the effects of short-term rates on the economy. However, there is some strand of the literature, both empirical and theoretical, that introduces this feature and finds that monetary policy is less effective when long-term rates are prevalent in the economy. For instance, Kiley (2014) finds that, empirically, for the US, the short-term interest rate has a larger influence on economic activity. De Bondt et al. (2005) find that, for the Euro area, retail bank interest rates adjust not only to changes in short-term interest rates but also to long-term rates, explaining the sluggishness of retail bank interest rates. Thus, as they suggest, the different degree of sluggishness in the national retail markets may introduce country asymmetries in the transmission of the single monetary policy. Reifschneider et al. (1999) assume that movements in long-term interest rates, coming from the expected path of shortterm rates affect overall financial conditions and aggregate demand. Abbassi and Linzert (2012) find that part of the loss in monetary policy effectiveness to money market rates during the crisis could be attributable to uncertainty about future interest rates. Cournede et al. (2008) show that a shift towards fixed-rate assets and liabilities may have contributed to a weaker transmission of monetary policy, which may also potentially risk financial stability. Chen et al. (2011) find that short-term interest rates have more powerful effects on aggregate demand than long-term ones. Rubio (2011), Calza et al. (2013), Garriga et al. (2013), and Brzoza-Brzezina et al. (2014) find that fixed-rate contracts, associated with longer-term interest rates, imply less effective monetary policy. My paper contributes to this literature by studying how the interest-rate sluggishness caused by longer-term rates, affects the effectiveness of the combination of monetary and macroprudential policies, not only to stabilize the macroeconomy but also the financial system.

In this paper, I build a new Keynesian dynamic stochastic general equilibrium model with housing. 
There are borrowers and savers in the economy. Borrowers take loans tied to the value of housing collateral. I introduce mortgage contracts that are either short term or long term. The short-term rate would be directly linked to the policy rate. The long-term one would be linked to expected short-term rates. In this way, I capture the fact that movements in long-term rates mainly come from changes in expectations about future short-term rates. In this framework, I study how the interest-rate sluggishness that comes from longer-term rates affects the effectiveness and optimal design of both monetary and macroprudential policies. Monetary policy is set by the central bank following a Taylor rule. For the macroprudential policies I consider two options; one in which they are conducted by the central bank with the interest rate as an instrument. That is, I include credit growth in the interest-rate rule of the central bank. In this way, the monetary authority would have one instrument, the interest rate, to take care of two objectives; macroeconomic and financial stability. In the second option, there is a macroprudential regulator that uses a countercyclical rule for the LTV as a macroprudential tool. ${ }^{1}$ Under this rule, the LTV would be the instrument of the macroprudential regulator and would react to credit growth. In this way, if the economy is, for instance, entering a credit boom, the LTV will be cut, thus restricting credit in the economy and avoiding excessive credit growth. This rule, which resembles a Taylor rule for monetary policy, serves as a proxy for the macroprudential instruments that have been used by some institutions.

Within this setting, in order to assess the effectiveness of monetary and macroprudential policies to stabilize the economy, I compute policy frontiers, also known as Taylor curves. I find that when interest rates are not sluggish, monetary policy is more stabilizing because there is a one-for-one link between the policy rate and the borrowing rate. With respect to macroprudential policies, their effectiveness will also depend on the sluggishness in the interest rate pass-through, since their interaction with monetary policy will have an effect on financial stability. Results show that monetary policy is effective to stabilize the financial system only with short-term rates but compromising macroeconomic stability. In the case of a macroprudential regulator that uses the LTV as an instrument, I show that it will also be more effective for financial stability purposes if interest rates are short term.

Then, I analyze how the optimality of monetary and macroprudential policies changes depending on whether retail rates are linked to short or longer-term rates. I define optimal policy as the one that

\footnotetext{
${ }^{1}$ LTV rules have become particularly popular. See for instance, Gruss and Sgherri (2009) analyse the welfare effects of procyclical LTV ratios in a real business cycle model with borrowing constraints. Funke and Paetz (2012) uses a non-linear rule on the LTV and finds that it can help reduce the transmission of house price cycles to the real economy. In a similar way, Kannan et al. (2012) examine a monetary policy rule that reacts to prices, output and changes in collateral values with a macroprudential instrument based on the LTV.
} 
maximizes total welfare. Results show that including a macroprudential objective in the Taylor rule for monetary policy does not imply much gains in terms of financial stability in either case, short or long-term rates. Having a separate macroprudential authority would increase financial stability only in the case of the short-term interest rates.

This paper relates to different strands of the literature. First, it introduces longer-term contracts in a DSGE model in the spirit of Rubio (2011) or Calza et al. (2013). However, those studies restrict themselves to the effects of this feature on business cycles and monetary policy, without analyzing the implications for macroprudential policies. Second, it is close to the recent macroprudential literature. On the one hand, it relates with papers in which macroprudential policies interact with monetary policy as in Kannan et al. (2012), Rubio and Carrasco-Gallego (2014), and Angelini et al. (2014). However, it explores how mortgage rates linked to longer-term rates affect the implementation of macroprudential policies. On the other hand, my paper also explores the topic of whether monetary and macroprudential policies should be conducted by the same regulator using only one instrument and two objectives or two regulators with two different instruments. Following the same line, Beau et al. (2012) claim that it is preferable to have a combination of separate objectives for monetary and macroprudential policies. Rubio and Carrasco-Gallego (2015) also find that monetary policy should focus on price stability while macroprudential policy should have financial stability as an instrument. Kannan et al. (2012) experiment with an augmented Taylor rule and an LTV rule and find that results depend on the source of the shock considered. In my paper, I find that having two separate instruments is preferred in the case of short-term rates.

The paper continues as follows. Section 2 presents the modelling framework. Section 3 discusses the effectiveness of monetary and macroprudential policies. Section 4 displays the optimal monetary and macroprudential policy mix. Section 5 presents the conclusions.

\section{The Baseline Model}

I consider an infinite-horizon economy in which households consume, work and demand real estate. There is a representative financial intermediary that provides mortgages and accepts deposits from consumers. Firms set prices subject to Calvo (1983)-Yun (1996) nominal rigidity. The monetary authority sets interest rates endogenously, in response to inflation and output, following a Taylor rule. For macroprudential policies I consider two options; one in which it is conducted by the central bank, which uses the interest 
rate to take care of financial stability; and a second one in which a separate macroprudential authority uses a countercyclical rule on the LTV to avoid excessive credit growth.

\subsection{The Consumer's Problem}

There are two types of consumers: savers and borrowers. Borrowers can borrow from the financial intermediary as long as they have housing collateral to secure their debt. As in Iacoviello (2005), I assume that borrowers are more impatient than savers. This assumption ensures that borrowers always borrow as much as they are offered, so that they do not save and wait until they have the funds to self-finance their consumption. This generates an economy in which households divide into borrowers and savers. All households derive utility from consumption, housing services (assumed proportional to the housing stock) and leisure.

\subsubsection{The Financial Intermediary}

There is a financial intermediary which accepts deposits from savers, and extends loans to borrowers. I consider that the financial intermediary offers two different mortgage products, depending on whether the interest rate is associated to short or longer-term rates. ${ }^{2}$

I consider a competitive framework and thus the intermediary takes the short-term interest rate as given, coming from the policy rate set by the central bank. In order for the two types of contracts to be offered, I assume that the intermediary is indifferent between the two of them. Hence, the expected discounted profits that the intermediary obtains by lending new debt in a given period at a rate tied to longer-term rates must be equal to the expected discounted profits the intermediary would obtain by lending at the short-term rate: ${ }^{3}$

$$
E_{\tau} \sum_{i=\tau+1}^{\infty} \beta^{i-\tau} \Lambda_{\tau, i} R_{\tau}^{L}=E_{\tau} \sum_{i=\tau+1}^{\infty} \beta^{i-\tau} \Lambda_{\tau, i} R_{i-1}^{S}
$$

where $\Lambda_{t, i}=\left(\frac{C_{t}^{u}}{C_{t+i}^{u}}\right)$ is the saver relevant discount factor. $R_{i}^{S}$ is the short-term interest rate set by the central bank, while $R_{\tau}^{L}$ is an interest rate associated with longer-term rates. Since the financial intermediary is owned by the savers, their stochastic discount factor is known and it is applied to the

\footnotetext{
${ }^{2}$ In countries where FRMs are most extensively used, financial intermediaries pass on the loans to investors with longterm liabilities (such as pension funds and life-insurance companies). Short-term deposits are predominantly used to finance mortgages in countries where ARMs are commonly used. These institutional features are out of the scope of this paper.

${ }^{3}$ The long-term rate loan is priced following this non-arbitrage condition, not by applying the prices of zero-coupon bonds to the future cash flows from the new loan.
} 
financial intermediary's problem. ${ }^{4}$

We can obtain the equilibrium value of $R_{\tau}^{L}$ from expression (1):

$$
R_{\tau}^{L}=\frac{E_{\tau} \sum_{i=\tau+1}^{\infty} \beta^{i-\tau} \Lambda_{\tau, i} R_{i-1}^{S}}{E_{\tau} \sum_{i=\tau+1}^{\infty} \beta^{i-\tau} \Lambda_{\tau, i}}
$$

Equation (2) states that, for every new debt issued at date $\tau, R_{\tau}^{L}$ is equal to a discounted average of future short-term interest rates, capturing the fact that long-term interest rates moves with changes on future expected short-term interest rates. ${ }^{5}$

As noted above, if any, profits from financial intermediation are rebated to the savers every period.

\subsubsection{Savers}

Savers maximize:

$$
\max E_{0} \sum_{t=0}^{\infty} \beta^{t}\left(\ln C_{t}+j \ln H_{t}-\frac{\left(L_{t}\right)^{\eta}}{\eta}\right),
$$

where $E_{0}$ is the expectation operator, $\beta \in(0,1)$ is the discount factor, and $C_{t}, H_{t}$ and $L_{t}$ are consumption at $t$, the stock of housing and hours worked, respectively; $1 /(\eta-1)$ is the labor supply elasticity, $\eta>0$ and $j>0$ represents the weight of housing in the utility function.

The budget constraint is:

$$
C_{t}+q_{t} H_{t}+b_{t} \leq q_{t} H_{t-1}+w_{t} L_{t}+\frac{R_{t-1} b_{t-1}}{\pi_{t}}+F_{t}+S_{t}
$$

where $q_{t}$ is the real housing price and $w_{t}$ is the real wage for savers. These can buy houses or sell them at the current price $q_{t}$. I assume zero housing depreciation for simplicity. As we will see, this group will choose not to borrow at all; they are the savers in this economy. $b_{t}$ is the amount they save. They receive interest $R_{t-1}$ for their savings. $\pi_{t}$ is inflation in period $t$. $S_{t}$ and $F_{t}$ are lump-sum profits received from the firms and the financial intermediary, respectively. We can think of these consumers as the wealthy agents in the economy, who own the firms and the financial intermediary.

\footnotetext{
${ }^{4}$ Calza et al. (2010) also have a model in which the financial intermediary offers fixed and variable-rate mortgages. However, in their model, the two types of mortgages do not coexist. For them, the fixed-rate loan is a two-period contract while the variable-rate is one period.

${ }^{5}$ We could also interpret the short-term rate as variable-rate loans. However, in the real world, variable-rate mortgages are also long-term loans. That is, both loans are amortized over a long period of time. The only difference is that interest payments on adjustable-rate mortgages are variable. In the model variable-rate mortgages are modeled as one-period loans.
} 
The first-order conditions for this unconstrained group are:

$$
\begin{gathered}
\frac{1}{C_{t}}=\beta E_{t}\left(\frac{R_{t}}{\pi_{t+1} C_{t+1}}\right), \\
w_{t}=\left(L_{t}\right)^{\eta-1} C_{t}, \\
\frac{j}{H_{t}}=\frac{1}{C_{t}} q_{t}-\beta E_{t} \frac{1}{C_{t+1}} q_{t+1} .
\end{gathered}
$$

Equation (5) is the Euler equation for consumption, equation (6) is the labor-supply condition, and equation (7) is the Euler equation for housing. This states that, at the margin, the benefits from consuming housing must be equal to the costs.

\subsubsection{Borrowers}

Borrowers and savers are different in the way they discount the future; borrowers are more impatient than savers, so that their discount factor is lower. As well, borrowers can access financial markets using housing collateral, that is, the amount they borrow is proportional to the value of their stock of housing:

$$
E_{t} \frac{R_{t}^{i}}{\pi_{t+1}} \widetilde{b}_{t} \leq k_{t} E_{t} q_{t+1} \widetilde{H}_{t}
$$

where $k_{t}$ represents a proxy for the loan-to-value ratio and, as we will see, it is the instrument of the macroprudential authority. ${ }^{6}$ As we have seen with the problem of the financial intermediary, the superscript $i=S, L$ indicates the fact that rates can be short or long term. By definition, $R_{t}^{S}=R_{t}$.

Borrowers maximize their lifetime utility function:

$$
\max E_{0} \sum_{t=0}^{\infty} \widetilde{\beta}^{t}\left(\ln \widetilde{C}_{t}+j \ln \widetilde{H}_{t}-\frac{\left(\widetilde{L}_{t}\right)^{\eta}}{\eta}\right)
$$

subject to the budget constraint:

$$
\widetilde{C}_{t}+q_{t} \widetilde{H}_{t}+\frac{R_{t-1}^{i} \widetilde{b}_{t-1}}{\pi_{t}} \leq q_{t} \widetilde{H}_{t-1}+\widetilde{w}_{t} \widetilde{L}_{t}+\widetilde{b}_{t}
$$

\footnotetext{
${ }^{6}$ The assumption of different discount factors is crucial for the collateral equation to be binding and therefore, for there to be both borrowers and savers in the economy.
} 
and (8).

The first-order conditions for borrowers are:

$$
\begin{gathered}
\frac{1}{\widetilde{C}_{t}}=\widetilde{\beta} E_{t}\left(\frac{R_{t}^{i}}{\pi_{t+1} \widetilde{C}_{t+1}}\right)+\lambda_{t} R_{t}^{i} \\
\widetilde{w}_{t}=\left(\widetilde{L}_{t}\right)^{\eta-1} \widetilde{C}_{t}, \\
\frac{j}{\widetilde{H}_{t}}=\frac{1}{\widetilde{C}_{t}} q_{t}-\widetilde{\beta} E_{t}\left(\frac{1}{\widetilde{C}_{t+1}} q_{t+1}\right)-\lambda_{t} k_{t} E_{t}\left(q_{t+1} \pi_{t+1}\right) .
\end{gathered}
$$

These first-order conditions differ from the ones of the savers. In the case of borrowers, the Lagrange multiplier on the collateral constraint $\left(\lambda_{t}\right)$ appears in equations (11) and (13). From the Euler equation for consumption of savers, we know that $R=1 / \beta$ in steady state. If we combine this result with the Euler equation for consumption of borrowers we have that $\lambda=(\beta-\widetilde{\beta}) / \widetilde{C}>0$ in the steady state. This means that equation (8) holds with equality in the steady state. Since we log-linearize the model around the steady state and assume that uncertainty is low, we can generalize this result to off-steadystate dynamics. Then, we can say that this equation is always binding, so that borrowers borrow the maximum amount they are allowed to and savers are never in debt. ${ }^{7}$

Given the borrowing amount implied by (8) at equality, consumption for borrowers can be determined by their flow of funds:

$$
\widetilde{C}_{t}=\widetilde{w}_{t} \widetilde{L}_{t}+\widetilde{b}_{t}+q_{t}\left(\widetilde{H}_{t-1}-\widetilde{H}_{t}\right)-\frac{R_{t-1}^{i} \widetilde{b}_{t-1}}{\pi_{t}}
$$

and the first-order condition for housing becomes:

$$
\frac{j}{\widetilde{H}_{t}}=\frac{1}{\widetilde{C}_{t}}\left(q_{t}-\frac{k_{t} E_{t}\left(q_{t+1} \pi_{t+1}\right)}{R_{t}^{i}}\right)-\widetilde{\beta} E_{t}\left(\frac{1}{\widetilde{C}_{t+1}}\left(1-k_{t}\right) q_{t+1}\right) .
$$

\footnotetext{
${ }^{7}$ This is a typical assumption for this kind of models. See Iacoviello (2005), Appendix C for a detailed analysis of when do constraints bind.
} 


\section{$2.2 \quad$ Firms}

\subsubsection{Final Goods Producers}

There is a continuum of identical final goods producers that aggregate intermediate goods according to the production function

$$
Y_{t}=\left[\int_{0}^{1} Y_{t}(z)^{\frac{\varepsilon-1}{\varepsilon}} d z\right]^{\frac{\varepsilon}{\varepsilon-1}}
$$

where $\varepsilon>1$ is the elasticity of substitution between intermediate goods. The final good firm chooses $Y_{t}(z)$ to minimize its costs, resulting in demand of intermediate good $z$ :

$$
Y_{t}(z)=\left(\frac{P_{t}(z)}{P_{t}}\right)^{-\varepsilon} Y_{t}
$$

The price index is then given by:

$$
P_{t}=\left[\int_{0}^{1} P_{t}(z)^{1-\varepsilon} d z\right]^{\frac{1}{\varepsilon-1}}
$$

Market clearing for the final good requires:

$$
Y_{t}=\bar{C}_{t}=C_{t}+\widetilde{C}_{t}
$$

\subsubsection{Intermediate Goods Producers}

The intermediate goods market is monopolistically competitive. Following Iacoviello (2005), intermediate goods are produced according to the production function:

$$
Y_{t}(z)=A_{t} L_{t}(z)^{\gamma} \widetilde{L}_{t}(z)^{(1-\gamma)}
$$

where $\gamma \in[0,1]$ measures the relative size of each group in terms of labor. This Cobb-Douglas production function implies that labor efforts of borrowers and savers are not perfect substitutes. This specification is analytically tractable and allows for closed-form solutions for the steady state of the model. This assumption can be economically justified by the fact that savers are the managers of the firms and their wage is higher than the one of the borrowers. ${ }^{8}$

\footnotetext{
${ }^{8}$ It could also be interpreted as the savers being older than the borrowers, therefore more experienced. Experimenting with a production function in which hours are substitutes leads to very similar results in terms of model dynamics. Under
} 
$A_{t}$ represents technology and it follows the following autoregressive process:

$$
\log \left(A_{t}\right)=\rho_{A} \log \left(A_{t-1}\right)+u_{A t}
$$

where $\rho_{A}$ is the autoregressive coefficient and $u_{A t}$ is a normally distributed shock to technology.

Labor demand is determined by:

$$
\begin{gathered}
w_{t}=\frac{1}{X_{t}} \gamma \frac{Y_{t}}{L_{t}}, \\
\widetilde{w}_{t}=\frac{1}{X_{t}}(1-\gamma) \frac{Y_{t}}{\widetilde{L}_{t}}
\end{gathered}
$$

where $X_{t}$ is the markup, or the inverse of marginal cost. ${ }^{9}$

The price-setting problem for the intermediate good producers is a standard Calvo-Yun setting. An intermediate good producer sells its good at price $P_{t}(z)$, and $1-\theta, \in[0,1]$, is the probability of being able to change the sale price in every period. The optimal reset price $P_{t}^{*}(z)$ solves:

$$
\sum_{k=0}^{\infty}(\theta \beta)^{k} E_{t}\left\{\Lambda_{t, k}\left[\frac{P_{t}^{*}(z)}{P_{t+k}}-\frac{\varepsilon /(\varepsilon-1)}{X_{t+k}}\right] Y_{t+k}^{*}(z)\right\}=0 .
$$

The aggregate price level is then given by:

$$
P_{t}=\left[\theta P_{t-1}^{1-\varepsilon}+(1-\theta)\left(P_{t}^{*}\right)^{1-\varepsilon}\right]^{1 /(1-\varepsilon)} .
$$

Using (23) and (24), and log-linearizing, we can obtain a standard forward-looking New Keynesian Phillips curve $\widehat{\pi}_{t}=\beta E_{t} \widehat{\pi}_{t+1}-\widetilde{k} \widehat{x}_{t}+u_{\pi t}$, that relates inflation positively to future inflation and negatively to the markup $(\widetilde{k} \equiv(1-\theta)(1-\beta \theta) / \theta) . u_{\pi t}$ is a normally distributed cost-push shock. ${ }^{10}$

the Cobb-Douglas specification each household has mass one. $\gamma$ is a constant that represents the labor-income share of the patient household and $L_{t}$ are total hours worked by the patient household. In the alternative specification, one needs to define the fraction of agents in the population, say $\omega$ is the fraction of savers. Then, $\omega L_{t}$ represents the total hours worked by the patient household. Therefore, both specifications are very similar but, while $\gamma$ represents the economic size of savers, $\omega$ is its absolute size.

${ }^{9}$ Symmetry across firms allows us to write the demands without the index $z$.

${ }^{10}$ Variables with a hat denote percent deviations from the steady state. 


\subsection{Aggregate Variables}

Economy-wide aggregates are: $\bar{C}_{t} \equiv C_{t}+\widetilde{C}_{t}, \bar{L}_{t} \equiv L_{t}+\widetilde{L}_{t}, \bar{H}_{t} \equiv H_{t}+\widetilde{H}_{t}$. In this model, aggregate supply of housing is fixed, so that market clearing requires: $\bar{H}_{t}=H .^{11}$

\subsection{Monetary Policy}

The model is closed with a Taylor Rule to describe the conduct of monetary policy by the central bank:

$$
R_{t}=\pi_{t}^{\left(1+\phi_{\pi}\right)}\left(Y_{t} / Y_{t-1}\right)^{\phi_{y}} R
$$

where $\phi_{\pi}, \phi_{y}>0$ measure the response of interest rates to current inflation and output growth, respectively. $R$ is the steady-state interest rate.

\subsection{Modelling Macroprudential Policies}

For the macroprudential policy, I will consider two options to be compared. The first one is an extended Taylor rule so that the interest rate, apart from responding to inflation and output, also responds to credit growth. The second one would be a rule on the LTV, so that this variable responds to credit growth.

The first case represents a world in which macroprudential and monetary policies are integrated and assigned to the central bank, which uses just one instrument, the interest rate, to achieve both macroeconomic and financial stability. In this case, the objectives of monetary policy should be expanded to include financial stability. The second case would correspond to a situation in which macroprudential supervision should involve a regulatory agency, different from the central bank or within the central bank, that uses a different instrument, namely the LTV, for macroprudential purposes.

\subsubsection{Macroprudential Taylor Rule}

Here, I am considering the case in which the central bank is adopting a macroprudential approach and taking care of credit variables. Thus, I extend the Taylor rule to not only respond to inflation and output growth but also to credit growth.

$$
R_{t}=\pi_{t}^{\left(1+\phi_{\pi}\right)}\left(Y_{t} / Y_{t-1}\right)^{\phi_{y}}\left(b_{t} / b_{t-1}\right)^{\phi_{b}} R
$$

\footnotetext{
${ }^{11}$ This assumption provides an easy way to specify the supply of housing and have variable prices. A two-sector model with production of housing would not generate qualitatively different results.
} 
Therefore, we are giving the central bank a way to implement a macroprudential policy. Notice that increasing the interest rate when credit is growing mean restricting credit booms in the economy, since debt repayments are going up. Then, in this case, the goals of the central bank are extended to also include financial stability.

\subsubsection{LTV Rule}

As an approximation for a realistic macroprudential policy, I consider a Taylor-type rule for the loan-tovalue ratio. In standard models, the LTV ratio is a fixed parameter which is not affected by economic conditions. However, we can think of regulations of LTV ratios as a way to moderate credit booms. When the LTV ratio is high, the collateral constraint is less tight. And, since the constraint is binding, borrowers will borrow as much as they are allowed to. Lowering the LTV tightens the constraint and therefore restricts the loans that borrowers can obtain. Recent research on macroprudential policies has proposed Taylor-type rules for the LTV ratio so that it reacts inversely to variables such that the growth rates of GDP, credit growth, the credit-to-GDP ratio or house prices. These rules can be a simple illustration of how a macroprudential policy could work in practice. Here, I assume that there exists a macroprudential Taylor-type rule for the LTV ratio, so that it responds to credit growth:

$$
k_{t}=k_{S S}\left(b_{t} / b_{t-1}\right)^{-\phi_{b}^{k}}
$$

where $k_{S S}$ is the steady-state value for the loan-to-value ratio. $\phi_{b}^{k} \geq 0$ measures the response of the loan-to-to value to credit growth. This kind of rule would deliver a lower LTV ratio in booms, when credit is growing, therefore restricting credit in the economy and avoiding a credit boom derived from good economic conditions.

\subsection{Parameter Values}

For calibration, I consider the following parameter values: The discount factor, $\beta$, is set to 0.99 so that the annual interest rate is $4 \%$ in the steady state. The discount factor for borrowers, $\widetilde{\beta}$, is set to 0.98. Lawrance (1991) estimates discount factors for poor consumers between 0.95 and 0.98 at quarterly frequency. Results are not sensitive to different values within this range. This value of $\widetilde{\beta}$ is low enough to endogenously divide the economy into borrowers and savers. The weight of housing on the utility function, $j$, is set to 0.1 in order for the ratio of housing wealth to GDP in the steady state to be 
consistent with the data. This value of $j$ implies a ratio of approximately 1.40 , in line with the Flow of Funds data. ${ }^{12}$ I set $\eta=2$, implying a value of the labor supply elasticity of $1 .{ }^{13}$ For the loan-to-value ratio, I consider $k_{S S}=0.9$, consistent with the evidence that in the last years borrowers took credit of more than $90 \%$ of the value of their house, on average. ${ }^{14}$ The labor income share of savers, $\gamma$, is set to 0.64, following the estimate in Iacoviello (2005). I pick a value of 6 for $\varepsilon$, the elasticity of substitution between intermediate goods. This value implies a steady-state markup of 1.2. The probability of not changing prices, $\theta$, is set to 0.75 , implying that prices change every four quarters. For the benchmark Taylor Rule parameters I use $\phi_{\pi}=0.5, \phi_{y}=0.5$. These values are consistent with the original parameter proposed by Taylor in 1993. Table 1 shows a summary of the parameter values.

\begin{tabular}{|c|c|c|}
\hline \multicolumn{3}{|c|}{ Table 1: Parameter Values } \\
\hline \hline$\beta$ & .99 & Discount Factor for Savers \\
\hline$\widetilde{\beta}$ & .98 & Discount Factor for Borrowers \\
\hline$j$ & .1 & Weight of Housing in Utility Function \\
\hline$\eta$ & 2 & Parameter associated with labor elasticity \\
\hline$k_{S S}$ & .9 & Loan-to-value ratio \\
\hline$\gamma$ & .64 & Labor share for Savers \\
\hline$X$ & 1.2 & Steady-state markup \\
\hline$\theta$ & .75 & Probability of not changing prices \\
\hline$\rho_{A}$ & .9 & Technology persistence \\
\hline$\phi_{\pi}$ & .5 & Inflation Parameter in Taylor Rule \\
\hline$\phi_{y}$ & .5 & Output Parameter in Taylor Rule \\
\hline
\end{tabular}

\section{The Effectiveness of Monetary and Macroprudential Policies}

In this section, I study the effectiveness of monetary and macroprudential policies to stabilize the macroeconomy and the financial system, both when interest rates are linked to short and long-term rates. In order to do that, I compute policy efficiency frontiers, also known as Taylor curves. These curves

\footnotetext{
${ }^{12}$ See Table B.100. In this model, consumption is the only component of GDP. To make the ratio comparable with the data I multiply it by 0.6 , which is approximately what nondurable consumption and services account for in the GDP, according to the data in the NIPA tables.

${ }^{13}$ Microeconomic estimates usually suggest values in the range of 0 and 0.5 (for males). Domeij and Flodén (2006) show that in the presence of borrowing constraints this estimates could have a downward bias of $50 \%$.

${ }^{14}$ In the US, the average LTV ratio exceeds $90 \%$ for the period 1973-2006. See the data from the Federal Housing Finance Board.
} 
represent the trade-offs that policy makers face when trying to achieve their objectives.

In the standard new Keynesian model, in which macroprudential policies are not considered, the central bank aims at minimizing the variability of output and inflation to reduce the distortion introduced by nominal rigidities and monopolistic competition. That is, the loss function that the central bank faces is $L_{C B}=\sigma_{\pi}^{2}+\lambda_{y} \sigma_{y}^{2}$, where $\sigma_{\pi}^{2}$ and $\sigma_{y}^{2}$ are the variances of inflation and output, respectively. $\lambda_{y} \geq 0$, represents the relative weight of the central bank to the stabilization of output. This loss function is consistent with a Taylor rule in which the interest rate responds to inflation and output, namely, equation (25). In this framework, monetary policy efficiency is assessed through a Taylor curve that shows, given different parameters of the Taylor rule, the parameter combinations that deliver the lower output and inflation variability. Therefore, a Taylor curve which is closer to the origin would represent a more efficient monetary policy. ${ }^{15}$

However, in models with collateralized debt, there are two types of distortions: price rigidities and credit frictions. This creates conflicts and trade-offs between borrowers and savers. Savers may prefer policies that reduce the price stickiness distortion. However, borrowers may prefer a scenario in which the pervasive effect of the collateral is softened. Borrowers operate in a second-best situation and cannot smooth consumption by themselves. Thus, a more stable financial system would provide them with a setting in which their consumption pattern is smoother. Therefore, financial stability may also be a policy objective. In this model, borrowers sign mortgages to buy houses, the asset of the model. Therefore, the financial system can be proxied by the amount of borrowing that takes place. Within this framework, I propose a measure for financial stability: a low variability of borrowing. In this sense, a lower variance of borrowing would imply a more stable financial system: if the variance of borrowing is lower, credit is smoother. There are studies that show that, in these kind of models, financial variables should be included in the loss function that the policy maker aims at minimizing. ${ }^{16}$ Angelini et al. (2012) assume that the loss function in the economy also contains financial variables, namely borrowing variability, as a proxy for financial stability. Then, there would be a loss function for the economy that would include not only the variability of output and inflation but also the variability of borrowing: $L_{C B}=\sigma_{\pi}^{2}+\lambda_{y} \sigma_{y}^{2}+\sigma_{b}^{2}$, where $\sigma_{b}^{2}$ is the variance of borrowing. ${ }^{17}$ This augmented loss function would be consistent with an extended Taylor rule that takes financial variables into account in the setting of the

\footnotetext{
${ }^{15}$ See for instance Iacoviello (2005) that evaluates with a policy frontier a Taylor rule responding to house prices.

${ }^{16}$ Andrés et al. (2013) find that optimal monetary policy may involve a trade-off between the stabilization of inflation, output gap, consumption gap and the distribution of the collateral asset between constrained and unconstrained consumers.

${ }^{17}$ This loss function would be consistent with studies that make a second-order approximation of the utility of individuals and find that it differs from the standard case by including financial variables.
} 
interest rate, that is, equation (26).

However, Svensson (2012) argues that conducting monetary policy and financial-stability policy in an integrated way may be inappropriate, since monetary policy and financial-stability policy are distinct and separate policies, with different objectives and different instruments. Svensson (2012) suggests that monetary policy should be in charge of price stability while macroprudential policy needs to address financial stability. In this case, the central bank and the macroprudential regulator are different and have separate objectives; macroeconomic and financial stability, respectively. Therefore, their loss functions

would be $L_{C B}=\sigma_{\pi}^{2}+\lambda_{y} \sigma_{y}^{2}$ and $L_{M P}=\sigma_{b}^{2}$. In this case, monetary policy would be conducted by the central bank through the standard Taylor rule (equation 25), while the macroprudential policy would be conducted by a regulatory agency following equation (27).

In the following subsection, I compute policy frontiers to assess the efficiency of monetary and macroprudential policies under short and long-term rates. I do the analysis for the three different cases described above:

1. A benchmark case, with no macroprudential policies, in which monetary policy aims at minimizing output and inflation variability and follows the Taylor rule represented by equation (25)

2. Monetary policy aims at minimizing output, inflation and credit variability and follows the augmented macroprudential Taylor rule in equation (26)

3. Monetary policy aims at minimizing output and inflation variability while macroprudential policy minimizes credit variability, following the Taylor rule in equation (25) and the LTV rule in equation (27), respectively

\subsection{Policy Efficiency Frontiers}

Case 1: Monetary Policy minimizes output and inflation variability Figure 1 shows the output and inflation variability frontier for the cases in which rates are tied to short and longer-term interest rates, respectively. This curve shows the trade-off that the central bank faces when trying to stabilize both output and inflation at the same time. Thus, given different parameters of the Taylor rule, it displays the combination that delivers the lower output and inflation variability. Therefore, as mentioned above, a Taylor curve which is closer to the origin means more efficient monetary policy. We see that when rates are linked to longer-term rates the efficiency frontier is further away from the origin. This means that, with long-term rates, monetary policy is less effective in stabilizing output and 


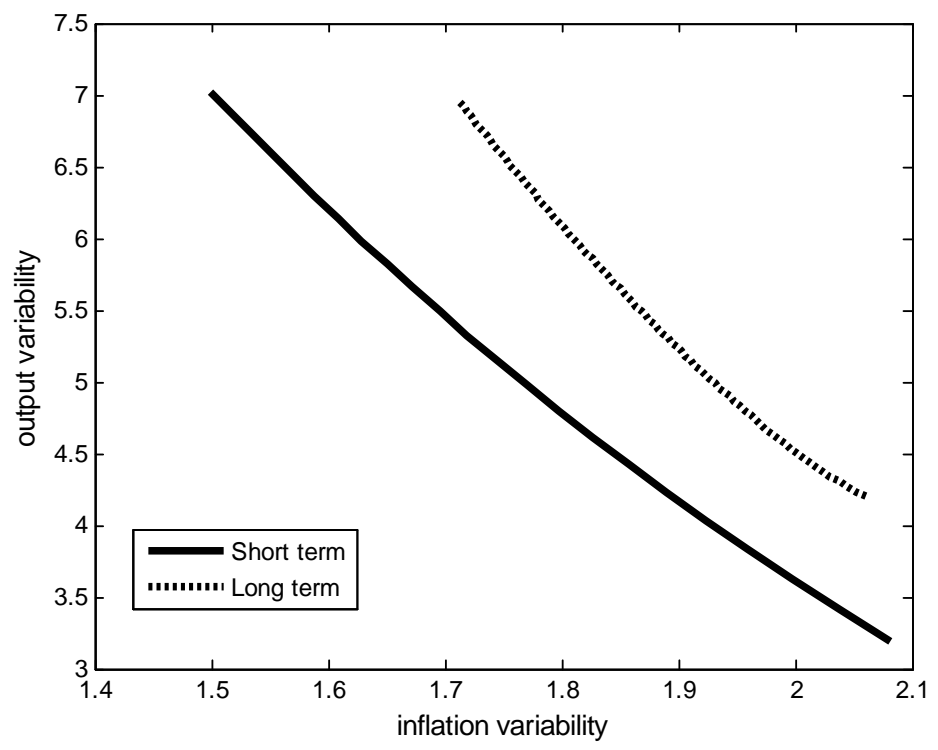

Figure 1: Taylor Curve. Monetary Policy aims at minimizing inflation and output variability

inflation because the link between monetary policy rates and effective rates is weaker. This creates a slower adjustment that prevents monetary policy from being as effective to stabilize output and inflation.

Case 2: Monetary Policy minimizes output, inflation and credit variability For the second case, I plot an extended efficiency frontier that includes the three objectives that the policy maker aims at minimizing: variability of output, variability of inflation and variability of borrowing. The last variable would represent financial stability.

Figures 2 and 3 present this augmented policy frontier which is three-dimensional on the variability of output, inflation and borrowing. The variability of output and inflation corresponds to the standard objectives of the central bank, while the third one would be an extra macroprudential objective. Figure 2 shows the frontiers for the short-term scenario, while figure 3 does it for the long-term rate. In each case, I compare the macroprudential Taylor rule with the standard one to see if adding the macroprudential objective to monetary policy increases financial stability. We see that for the short-term scenario, the curve corresponding to the augmented Taylor rule is further away from the inflation and output variability axes, but it is reflecting lower values of credit variability. This means that there are gains in term of financial stability, at the expense of macroeconomic stability. This suggests that adding this new objective to monetary policy helps stabilize the financial system but creates conflicts with macroeconomic 
variables, as Svensson (2012) suggested. This is a common result in the macroprudential literature. ${ }^{18}$ Nevertheless, figure 3 displays the same information for the long-term rate. Here, we can observe that including financial variables in the Taylor rule and extending the objectives of the central bank to also include financial stability does not represent an improvement in terms of stability, neither financial nor macroeconomic, since the two curves are virtually identical. With long-term interest rates, given the slow adjustment process that it creates, monetary policy is not effective to achieve this third objective either.

We can conclude for this case that, with short-term rates, monetary policy is not only effective to stabilize the macroeconomy but also to stabilize the financial system, by extending its objectives. However, with longer-term rates, monetary policy is not effective for any of the three objectives.

\section{Case 3: Monetary Policy minimizes output and inflation variability, Macroprudential} Policy minimizes credit variability In this case, monetary policy behaves in the standard way, taking care of macroeconomic stability. Thus, the Taylor curve that we should take into consideration for output and inflation variability is still figure 1. In order to show the effects of the LTV rule on financial stability, I display figure 4, in which I present how credit variability changes when increasing the aggressiveness of the macroprudential rule, that is, increasing the reaction parameter to credit growth in equation (27). We see that in this case, although we start from a situation with more financial instability in the long-term scenario, even with long-term rates, macroprudential policy is somewhat effective to stabilize the financial system but not as effective as in the short-term case. When a macroprudential regulator takes care of financial stability, this objective can be achieved in both cases. However, the interaction between the macroprudential rule and monetary policy is more effective when there are short-term rates in the economy because the policy rate has immediate effects.

Therefore, for all cases analyzed, policies, both monetary and macroprudential, are less effective with long-term rates. With long-term interest rates, monetary policy is less effective to stabilize the macroeconomy and not effective at all to stabilize the financial system, even if including this objective as an extra policy goal. If the macroprudential policy is implemented by an external regulator, it can achieve some improvement in terms of financial stability, which is more significant in the short-term case because the interactions between macroprudential and monetary policies are more effective.

\footnotetext{
${ }^{18}$ This is a typical result found in the literature. Results are in line, for example, with Gelain et al. (2013) which show that while macroprudential policies can stabilize some variables, they can magnify the volatility of others, especially inflation.
} 


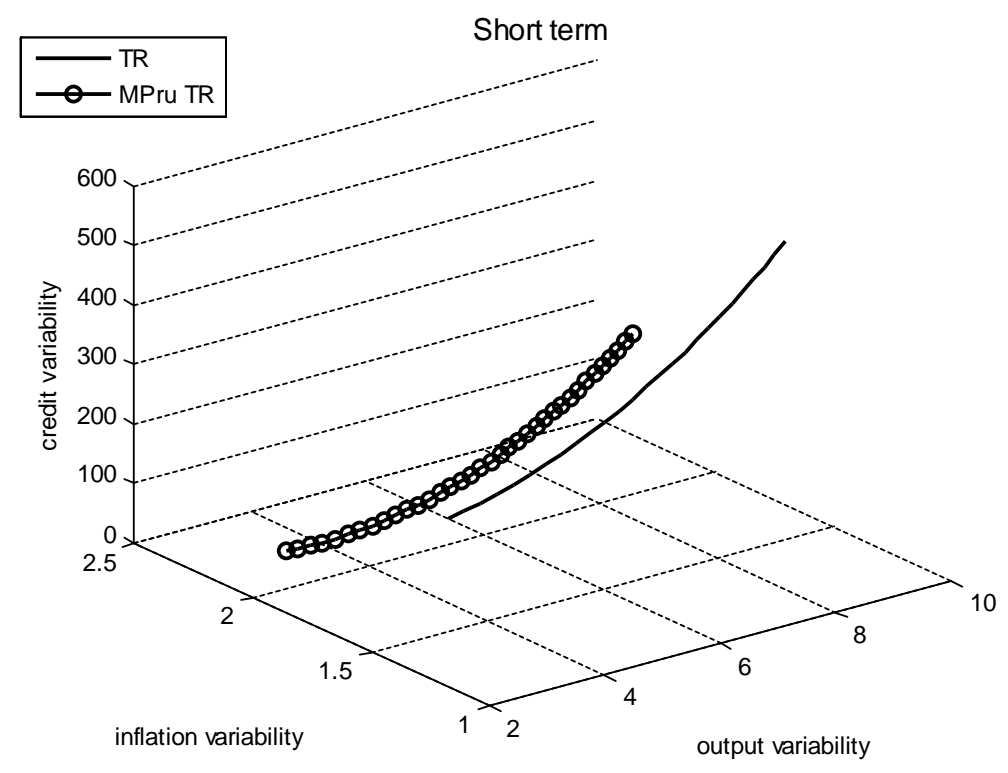

Figure 2: Augmented Taylor curve. Short-term rates. Monetary Policy minimizes output, inflation and credit variability

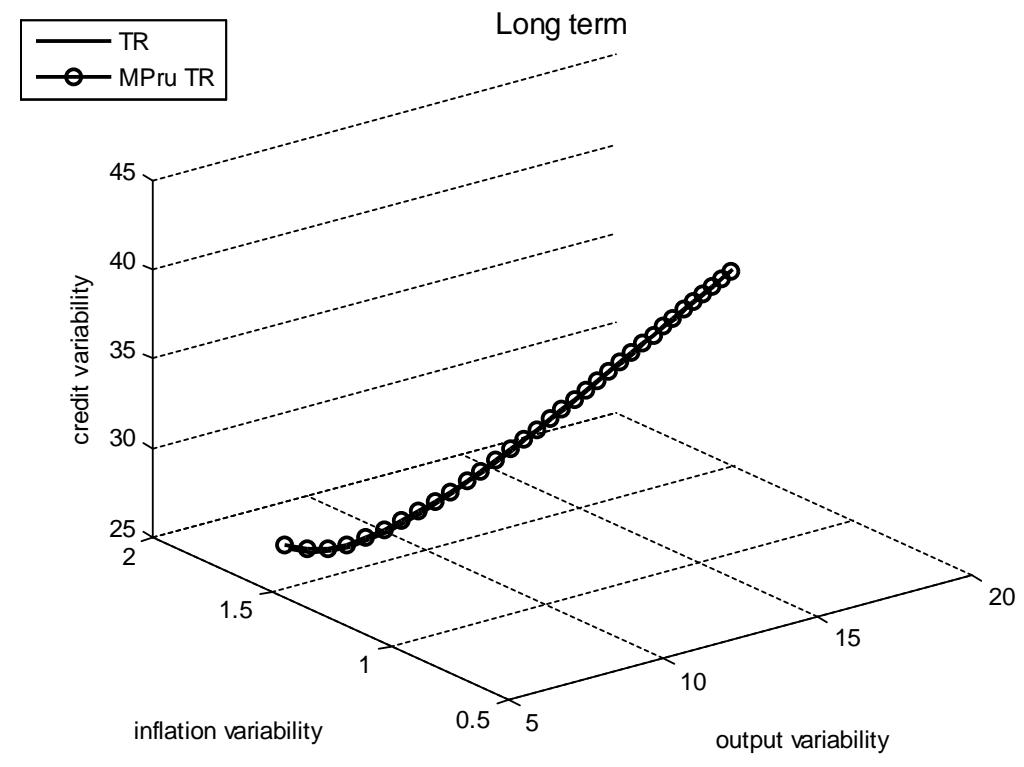

Figure 3: Augmented Taylor curve. Long-term rates. Monetary Policy minimizes output, inflation and credit variability 


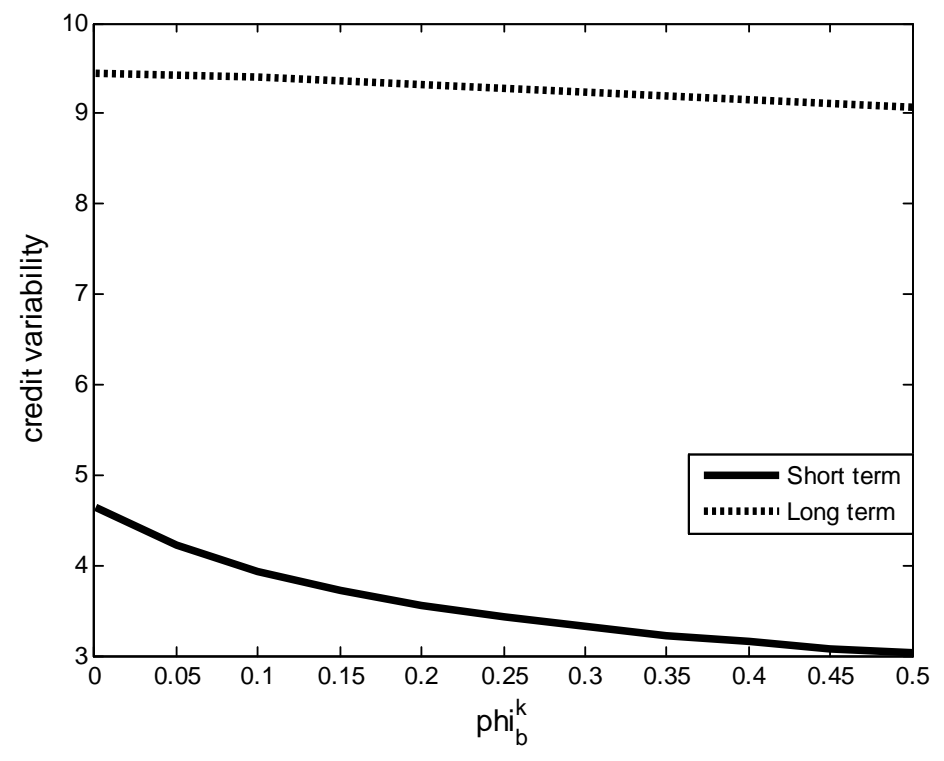

Figure 4: Credit variability implied by an LTV macroprudential rule

\section{Optimal Policy}

In this section, I analyze the optimality of monetary and macroprudential policies for both short and longer-term rates. ${ }^{19} \mathrm{I}$ find the optimal parameters of the different rules that maximize welfare and are most beneficial for both macroeconomic and financial stability. ${ }^{20}$ In particular, given a grid of possible parameters for the LTV and the Taylor rule (both the standard and the macroprudential one), I perform a search that maximizes welfare, subject to determinacy requirements. ${ }^{21}$ Table 2 displays the optimal parameters both for the short and the long-term rate cases:

\footnotetext{
${ }^{19}$ I define optimal policy as the one that maximizes total welfare.

${ }^{20}$ I solve the model by using a second-order approximation to the structural equations for given policy and then evaluatie welfare using this solution. I do this for borrowers and savers separately and then aggregate the individual welfare.

${ }^{21}$ The Taylor Principle also holds in the model with collateral constraints, for $\left(1+\phi_{\pi}\right) \leq 1$, there is indeterminacy.
} 


\begin{tabular}{|c|c|c|c|c|c|c|}
\hline & \multicolumn{3}{|c|}{ Short-Term Rate } & \multicolumn{3}{|c|}{ Long-Term Rate } \\
\hline & $\mathrm{TR}$ & Macropru TR & LTV Rule & $\mathrm{TR}$ & Macropru TR & LTV Rule \\
\hline$\left(1+\phi_{\pi}^{*}\right)$ & 2.2 & 2.2 & 2 & 1.1 & 1.1 & 1.1 \\
\hline$\phi_{y}^{*}$ & 1.4 & 1.1 & 1.4 & 0 & 0 & 0 \\
\hline$\phi_{b}^{k *}$ & - & - & 0.3 & - & - & 0.01 \\
\hline$\phi_{b}^{*}$ & - & 0.3 & - & - & 0.01 & - \\
\hline \multicolumn{7}{|c|}{ Volatilities } \\
\hline $\boldsymbol{\sigma}_{\pi}$ & 0.20 & 0.15 & 0.23 & 0.87 & 0.99 & 0.87 \\
\hline $\boldsymbol{\sigma}_{y}$ & 1.93 & 2.00 & 1.88 & 2.25 & 2.30 & 2.26 \\
\hline $\boldsymbol{\sigma}_{b}$ & 1.46 & 1.54 & 1.17 & 60.55 & 70.12 & 60.57 \\
\hline
\end{tabular}

Results in Table 2 display the optimal policy parameters and the volatilities implied by each combination, to assess the effectiveness of this specific policy to stabilize both the macroeconomy and the financial system. The table is divided into two parts corresponding to the short and the long-term rate case.

The first column in each case, represents the benchmark, since it does not include macroprudential policies. In this column we can find the optimal parameters of the standard Taylor rule for monetary policy, that is, the reaction parameters for inflation and output. We see that for the short-term case, it is optimal for monetary policy to respond more aggressively both against inflation and output. However, for long-term rates, since the link between the interest rate and the macroeconomic variables is weaker, it is not optimal for monetary policy to respond strongly to any of the variables because in any case, the effect of nominal rates on the economy is slower because they take more time to adjust. In terms of stability, we see from the volatilities that a greater stability, both macroeconomic and financial, is achieved with short-term rates. Macroeconomic stability is achieved because monetary policy is more effective with short-term rates. With long-term rates, since the nominal rate is linked to future expectations, the real rate depends more strongly on current inflation, and this one is more volatile than in the short-rate case because of the lack of effectiveness of monetary policy. Therefore, current real rates are more volatile. All this generates greater financial instability as compared to the short-term scenario.

In the second column of results, I find the optimal parameters for the augmented Taylor rule, that is, the macroprudential Taylor rule in which the interest rate does not only respond to inflation and 
output but also to credit growth. Results show that, for both the short and the long-term interest rate, although it is optimal to respond to credit growth, the optimal monetary policy is very similar to the case in which the central bank only responds to inflation and output. However, in neither case, greater financial stability is achieved. We saw in the previous section with the policy frontiers that for the short-term scenario, financial stability was achieved only at the expense of higher macroeconomic stability. Therefore, if monetary policy does not want to compromise inflation and output variability, it cannot achieve its new extra goal. For the long-term case, as we also saw previously, monetary policy is not effective either to achieve financial stability, even if responding to credit growth.

Finally, the third column in Table 2 presents the optimized monetary policy when it interacts with an LTV rule. We see that, for the short-term scenario, the optimal response for monetary policy is still very similar to the other cases analyzed. However, the macroprudential LTV rule complements the role of monetary policy and both interacting together manage to achieve a more stable financial scenario, with similar macroeconomic volatilities. For the long-term rates, the optimal response is also very similar to the benchmark case and there is no much improvement in terms of macroeconomic of financial stability because, since rates take longer to adjust, the interaction between both policies is not as effective as in the short-term case.

Results from Table 2 convey what we learned in the previous section. Including a macroprudential objective in the Taylor rule for monetary policy does not signify much gains in terms of financial stability in either case. Having a separate macroprudential authority, would increase financial stability only in the case of the short-term interest rates because of the interaction between the LTV rule and monetary policy.

\section{Conclusions}

In this paper, I study the ability of monetary and macroprudential policies to affect financial markets and the macroeconomy, both when interest rates in the economy are tied to short or longer-term rates. I develop a New Keynesian general equilibrium model with housing to analyze the combined effects of macroprudential and monetary policies under these two scenarios. There are borrowers and savers. Borrowers use their housing collateral to access credit markets.

I propose two types of macroprudential policies. The first one is a Taylor rule for the interest rate, in which rates would respond not only to inflation and output but also to credit growth. In this case, 
both monetary and macroprudential policies would be implemented by the central bank with a single instrument, the interest rate. The second one is a Taylor-type rule on the LTV. In this case, monetary and macroprudential policies would be implemented separately. The LTV would be the instrument of the macroprudential regulator, responding to credit growth.

In order to assess the effectiveness of monetary and macroprudential policies, I perform a policy frontier analysis. First, I compute Taylor curves for a standard monetary policy which aims at minimizing inflation and output variability and I find that when rates are linked to the short-term policy rate, monetary policy is more effective to stabilize the macroeconomy. Then, I extend the objectives of the central bank to also include financial stability and I calculate augmented Taylor curves that include these three objectives. Results show that, for the short-term case, monetary policy can achieve higher financial stability but only at the expense of more variability in the macroeconomic variables. For the long-term case, monetary policy is not effective to stabilize financial markets. Finally, I analyze the ability of a macroprudential LTV rule to enhance financial stability. I find that this rule is effective for this purpose, significantly for the short-term scenario and just marginally for longer-term rates.

In light of these results, I analyze the optimal monetary and macroprudential policy that maximizes welfare, both when rates are short term and when they are longer term. To start with, I perform the analysis for the benchmark case, the one that does not include macroprudential policies and monetary policy only cares about macroeconomic stability. For the short-term rate scenario, it is optimal for monetary policy to respond both against inflation and output. However, for longer-term rates, since the link between the interest rate and the macroeconomy is weaker, it is not optimal for monetary policy to respond to any of the two variables. A greater stability, both macroeconomic and financial, is achieved with short-term rates. Then, I study the optimality implications of including credit growth directly in the Taylor rule for the interest rate. For the short-term case, the optimal parameters do not deliver a situation with higher financial stability because that would only happen compromising macroeconomic stability. For longer-term rates, monetary policy is not effective to stabilize financial markets either. The last case I study is the optimality of monetary policy interacting with the LTV rule. For short-term rates, this option is effective to improve financial stability. However, it is not effective with longer-term rates.

In conclusion, both monetary and macroprudential policies are less effective with long-term rates. In the long-term case, monetary policy is less effective to stabilize the macroeconomy and not effective at all to stabilize the financial system, even if including financial stability as an extra policy goal. If the 
macroprudential policy is implemented using an LTV rule, financial stability improves with short-term rates but the improvement is just marginal with longer-term ones. 


\section{References}

[1] Abbassi, P., Linzert, T., (2012), "The effectiveness of monetary policy in steering money market rates during the financial crisis," Journal of Macroeconomics, 34 (4), pp. 945-954

[2] Andrés, J., Arce, O., Thomas, C., (2013), "Banking Competition, Collateral Constraints and Optimal Monetary Policy," Journal of Money, Credit and Banking, 45(s2), pp. 87-125

[3] Angelini, P., Neri, S., Panetta, F., (2014), "The Interaction between Capital Requirements and Monetary Policy." Journal of Money, Credit and Banking, 46 (6), pp. 1073-1112

[4] Beau, D., Clerc, L., Mojon, B., (2012), Macro-prudential policy and the conduct of monetary policy, mimeo, Bank of France

[5] Boivin, J., M. T. Kiley, and F. S. Mishkin, (2010), "How Has the Monetary Transmission Mechanism Evolved Over Time?" In Handbookof Monetary Economics, 1st ed., Vol. 3, ed. B. M. Friedman and M. Woodford, 369-422 (chapter 8). Elsevier

[6] Brzoza-Brzezina, M., Gelain, P., Kolasa, M., (2014), Monetary and macroprudential policy with multiperiod loans, NBP Working Paper No. 192

[7] Calza, A., Monacelli, T., Stracca, L., (2013), Housing Finance and Monetary Policy, Journal of the European Economic Association

[8] Calvo, G., (1983), "Staggered Prices in a Utility-Maximizing Framework", Journal of Monetary Economics, 12 (3), 383-398

[9] Chen, H., V. Curdia, and A. Ferrero, (2011), "The Macroeconomic Effects of Large-Scale Asset Purchase Programs," Staff Report No. 527, Federal Reserve Bank of New York

[10] Cournède, B., R. Ahrend and R. W. Price (2008), "Have Long-term Financial Trends Changed the Transmission of Monetary Policy?", OECD Economics Department Working Papers, No. 634, OECD Publishing, Paris

[11] De Bondt, G., Mojon, B., Valla, N., (2005), Term Structure and the Sluggishness of Retail Bank Interest Rates in Euro Area Countries, ECB Working Paper 518

[12] Domeij, D., Flodén, M., (2006), "The Labor-Supply Elasticity and Borrowing Constraints: Why Estimates are Biased", Review of Economic Dynamics, 9, 242-262

[13] Funke, M., Paetz, M., (2012), A DSGE-Based Assessment of Nonlinear Loan-to-Value Policies: Evidence from Hong Kong, BOFIT Discussion Paper No. 11/2012

[14] Garriga, C., Kydland, F. E., Sustek, R., (2013), Mortgages and Monetary Policy, NBER Working Paper No. 19744

[15] Gelain, P., Lansing, K., Mendicino, C., (2013), "House Prices, Credit Growth, and Excess Volatility: Implications for Monetary and Macroprudential Policy", International Journal of Central Banking, $9(2)$ 
[16] Gruss, B., Sgherri, S., (2009), The Volatility Costs of Procyclical Lending Standards: An Assessment Using a DSGE Model, IMF Working Paper, 09/35

[17] Iacoviello, M., (2005), "House Prices, Borrowing Constraints and Monetary Policy in the Business Cycle", American Economic Review, 95 (3), 739-764

[18] Kannan, P., Rabanal, P., Scott, A., (2012), "Monetary and Macroprudential Policy Rules in a Model with House Price Booms", The B.E. Journal of Macroeconomics, Contributions, 12 (1)

[19] Kiley, M., (2014), "The Aggregate Demand Effects of Short- and Long-Term Interest Rates," International Journal of Central Banking

[20] Lawrance, E., (1991), "Poverty and the Rate of Time Preference: Evidence from Panel Data", The Journal of Political Economy, 99 (1), 54-77

[21] Reifschneider, D., Tetlow, R., Williams, J., (1999), “Aggregate Disturbances, Monetary Policy, and the Macroeconomy: The FRB/US Perspective," Federal Reserve Bulletin 1-1

[22] Rubio, M., (2011), "Fixed- and Variable-Rate Mortgages, Business Cycles, and Monetary Policy," Journal of Money, Credit and Banking, 43 (4), 657-688

[23] Rubio, M., Carrasco-Gallego, J.A., (2014), "Macroprudential and Monetary Policies: Implications for Financial Stability and Welfare", Journal of Banking and Finance

[24] Rubio, M., Carrasco-Gallego, J.A., (2015), "Macroprudential and Monetary Policy Rules: A Welfare Analysis," The Manchester School, 83 (2)

[25] Svensson, L., (2012), Central-banking challenges for the Riksbank: Monetary policy, financialstability policy and asset management, CEPR Discussion Papers 8789

[26] Yun, T., (1996), "Nominal Price Rigidity, Money Supply Endogeneity and Business Cycles", Journal of Monetary Economics, 37, 175-391 